\title{
CORRECTION
}

\section{Correction to: Outcomes of mothers and newborns to prenatal exposure to kratom: a systematic review}

Mary Ellen Wright (iD, Claire Ginsberg, Abigail M. Parkison, Melissa Dubose, Madison Sherbondy and Emily Shores

(C) The Author(s), under exclusive licence to Springer Nature America, Inc. 2021

Journal of Perinatology (2022) 42:420; https://doi.org/10.1038/s41372-021-01212-5

Correction to: Journal of Perinatology; https://doi.org/10.1038/ s41372-021-00952-8
In this article Madison Sherbondy at affiliation Clemson University School of Nursing, Greenville, SC, USA was missing from the author list. The original article has been corrected. 